\title{
Knowledge, Adoption and Significant Difference among Respondents of Agricultural Services (TADP)
}

\author{
Sonali Sharma $^{1 *}$, H. R. Sain ${ }^{2}$, B. L. Dangi ${ }^{3}$, Rajshree Upadhyay ${ }^{4}$ \\ and Bhupendra Upadhyay ${ }^{5}$
}

${ }^{1}$ Home Science, ${ }^{2}$ Agriculture Extension, ${ }^{3}$ SMS Animal Husbandry, KVK-Barmer (Raj.), India

${ }^{4}$ Department of Home Science Extension and Communication Management, College of Home Science MPUAT, Udaipur, (Raj.), India

${ }^{5}$ Department of Statistics, Rajasthan College of Agriculture, MPUAT, Udaipur, (Raj.), India

*Corresponding author

Keywords

Knowledge, adoption, Agricultural services, TADP

Article Info

Accepted:

15 January 2020

Available Online:

10 February 2020
The present study was undertaken with the objectives to study the overall knowledge and adoption of beneficiaries and non-beneficiaries towards agricultural services promoted under Triabl Area Development Programme and significant difference in knowledge and adoption for agricultural services. The study was carried out in randomly selected 24 villages from three tribal blocks. The sample consisted of 360 respondents (180 beneficiaries and 180 non - beneficiaries) of Agricultural services of TADP selected on the basis of random sampling method. For statistical analysis, MPS, t-test and gap\% were used. Significant difference was found in the over all knowledge and over all adoption of beneficiaries and nonbeneficiaries in all the Agricultural services of TADP.

\section{Introduction}

The concern for tribal development, therefore, appears to be oriented towards bridging the gap between the Tribal's and the non-tribals, so that the latter can become partners in the new productive process and development programmmes. This obviously means that the income level of the tribal's must increase. Though development is popularly regarded as an economic process, equal emphasis should be placed on the qualitative aspects of the human development. Sociologically speaking, development should be looked upon as an organized activity with the aim of satisfying certain basic needs and to psychologically orient the tribal's to adopt new skills, attitudes, and life styles, so that they build up the inner strength, and appropriate social and cultural infra-structure to stand the pressures of the new situation and accrue benefits from the new programmes and maintain higher 
levels. For this point of view, development in a multidimensional process to progressively improve the social, cultural, economic and human conditions of the people. Therefore, the formulation of the development projects requires a clear methodology of approach not only in delimiting of defining the beneficiaries of the programmes and policies but also to involve specialists from all the fields of study relevant for development including social workers and administrators. During the past few decade, particularly since, independence enough has been said about the backwardness of the tribal communities in India and the need for their upliftment. Almost every kind of professional, anthropologist, social worker, bureaucrat, journalist, politician and others have held seminars, meetings and have offered suggestions to improve the tribal way of live. This still continues but what has been the overall outcome? Can we say that we have able to prepare a development strategy which can be beneficial to all the tribal communities? Have we been able to pose the right kind of question? I think after many trials and failures, we have not succeeded in attaining anything substantial at least exercise of the past four decades have made us realize that are no clear cut common problems for all the tribal groups in all country. As they vary in their habitation pattern, economy, degree of isolation, and culture change, social cohesiveness, etc. their problems also change.

With the view to bring the tribal areas or people of the country in the mainstream of economic development and accelerating the pace of socio-economic development, the State Government has made significant efforts to uplift the tribal people and started various activities for their social and economic development. A special programme, known as Tribal Area Developmental Programme (TADP) was taken up, on a pilot basis under a central sector plan scheme of the Ministry of Agriculture in 1964. Specific provisions have been made for funding the scheme targeting the well-being of the tribal people. Agricultural services of TADP are important aspect and six services of the programme helping out farmers in little benefits for life. Knowledge and adoption of the services are an another important criteria where effectiveness of the programme can be assessed correctly, in package of practices knowledge and adoption gap is also help out to carry practices in right and scientific manner.

\section{Materials and Methods}

This study involved interview method for 360 respondents of six Agricultural services of TADP in 12 villages of 3 blocks selected randomly.

\section{Knowledge test}

Knowledge test included questions for all six Agricultural services. Knowledge of the respondents was judged under two heads viz. information about the Agricultural service and specific information about improved practices of the Agricultural services. There was variation in number of components, questions and scores in each service, therefore service wise questions with their components and scores are given in Table A:

\section{Measurement of adoption}

Since the maximum scores varied for each Agricultural service, the scores obtained by the respondents were converted into Mean Percent Scores (MPS). The respondents were then categorized into three categories based on equal interval as follows:

\section{Measurement of adoption}

In Agricultural services, adoption of improved practices on various aspects was measured. There was variation in number of 
aspects, improved practices and scores in each Agriculture service as presented in Table C:

The respondents were categorized according to MPS in three equal interval categories as high, medium and low adoption, given in Table D:

Statistical analysis includes frequency, percentage, MPS, Student t-test and Paired ' $t$ ' test.

\section{Results and Discussion}

Overall Knowledge of the respondents about improved practices related to agricultural services of TADP

The overall knowledge of respondents related to each agricultural service, was assessed by the application of Student ' $t$ ' test between knowledge scores of beneficiaries and nonbeneficiaries to see the significance of difference. The related data are presented in Table 1.

Significant difference was found in overall knowledge of the beneficiaries and non beneficiaries in all the Agriculture services of TADP viz Agriculture Implements and Tools Distribution, Vegetable development, Horticulture Development, Barren Land Development through Jatropha Plantation, Livestock Development centre and Development of Whole (Agriculture) Tribal Villages and the MPS for all the services ranged between $67.56-84.79$ and for the non - beneficiaries MPS ranged from 15.89 to 59.21 .

Over all it can be inferred from the knowledge of respondents that beneficiaries were in good or average knowledge categories while non-beneficiaries were in average or poor knowledge categories.
The good knowledge of beneficiaries as compared to non-beneficiaries in all the agriculture services can be attributed to the effective programme implementation as the beneficiaries of each service were provided training regarding improved practices of agriculture, horticulture, animal rearing and related services. Beneficiaries were also receiving the benefits of the service like tools, seeds, fertilizers, free Artificial insemination and medicines for animals etc. Further programme personnel provide regular help in terms of information, guidance etc. to the beneficiaries as and when needed by them.

\section{Overall adoption of improved practices related to Agricultural services of TADP by the respondents}

Over all adoption among respondents of Agricultural services i.e. Agriculture Implements and Tools Distribution, Vegetable development, Horticulture Development, Development of Barren land through Jatropha plantation, Livestock Development centre and Development of Whole (Agriculture) Tribal Villages was calculated. Further Student's ' $t$ ' test was computed between adoption scores of beneficiaries and non - beneficiaries of six Agricultural services and presented in Table 2.

The table illustrate that highly significant difference was found in over all adoption of improved practices by the beneficiaries and non - beneficiaries in all the Agricultural services of TADP. This means that the beneficiaries of TADP had more adoption of improved practices in all the Agricultural services as compared to non - beneficiaries of the programme.

Review of Table 2 according to each services further reveal that in the Agriculture Implements and Tools Distribution, beneficiaries adopted to the medium extent 
with MPS 63.03 and non-beneficiaries were in low extent of adoption with MPS 6.21.

In Vegetable Development service, beneficiaries had high extent of adoption as MPS was 77.91. In case of non-beneficiaries adoption level in Vegetable Development service, MPS was 53.52 also depict medium extent of adoption (Table 2)

Data in the table further shows that adoption of Horticulture Development service was found to be high among beneficiaries with 87.15 MPS and of the non-beneficiaries medium with 52.35 MPS.

Review of Table 2 further depicts that beneficiaries had high extent of adoption of Jatropha Plantation where as nonbeneficiaries had medium extent of adoption as evident from MPS 69.74 and 42.05 respectively.

In adoption of Livestock Development (Table

2) beneficiaries had high extent of adoption with 75.80 MPS. In case of non-beneficiaries, MPS 55.40 in Livestock Development indicates medium extent of adoption.

The table further depicts the high adoption of Development of Whole (Agriculture) Tribal Villages service by beneficiaries with MPS
75.66 and medium adoption of nonbeneficiaries with 46.69 MPS.

The high adoption of beneficiaries as compared to non-beneficiaries in all the agriculture services can be attributed to the perception and receipt of benefits of services by the respective beneficiaries as well as regular follow up of the programme service by the concerned personnel to help them in the adoption of services by the beneficiaries.

Gap in knowledge and adoption of agricultural services among beneficiaries

The gap between knowledge and adoption of various improved practices related to services among the beneficiaries was derived by MPS and to see the significance of difference paired' $t$ ' test was applied on raw scores of knowledge and adoption and obtained results are presented in Table 3.

Data in the table depicts that significant difference was found in knowledge and adoption of all the Agricultural services at 1 per cent or 5 per cent level except in the service of Livestock Development where non significant difference was found in knowledge and adoption of the practices among beneficiaries.

Table.A Service wise details of the knowledge test

\begin{tabular}{|c|c|c|c|c|}
\hline S.No. & Agricultural services & $\begin{array}{l}\text { Number of } \\
\text { Components }\end{array}$ & $\begin{array}{l}\text { Number of } \\
\text { questions }\end{array}$ & Total res \\
\hline 1 & $\begin{array}{l}\text { Agriculture Implements and Tools } \\
\text { Distribution }\end{array}$ & 10 & 27 & 29 \\
\hline 2 & Vegetable Development & 14 & 16 & 30 \\
\hline 3 & Horticulture Development & 10 & 32 & 47 \\
\hline 4 & $\begin{array}{l}\text { Development of Barren land through } \\
\text { Jatropha Plantation }\end{array}$ & 11 & 34 & 53 \\
\hline 5 & Livestock Development & 5 & 33 & 47 \\
\hline 6 & $\begin{array}{l}\text { Development of whole (Agriculture) } \\
\text { tribal villages }\end{array}$ & 4 & 99 & 147 \\
\hline
\end{tabular}


Table.B Knowledge categories of the respondents

\begin{tabular}{|c|c|c|}
\hline S.No. & Categories & Score Range \\
\hline $\mathbf{1}$ & Good & $66.67-100$ \\
$\mathbf{2}$ & Average & $33.34-66.66$ \\
$\mathbf{3}$ & Poor & $0-33.33$ \\
\hline
\end{tabular}

Table.C Service wise details of adoption scale

\begin{tabular}{|c|c|c|c|c|}
\hline S.No & Agricultural Services & $\begin{array}{l}\text { Number of } \\
\text { Aspects }\end{array}$ & $\begin{array}{c}\text { Number of } \\
\text { practices }\end{array}$ & $\begin{array}{l}\text { Maximum } \\
\text { Score }\end{array}$ \\
\hline 1 & $\begin{array}{c}\text { Agriculture Implements and Tools } \\
\text { Distribution }\end{array}$ & 11 & 11 & 22 \\
\hline 2 & Vegetable Development & 10 & 10 & 20 \\
\hline 3 & Horticulture Development & 17 & 17 & 34 \\
\hline 4 & $\begin{array}{c}\text { Development of Barren Land through } \\
\text { Jatropha Plantation }\end{array}$ & 13 & 13 & 26 \\
\hline 5 & Livestock Development & 4 & 20 & 40 \\
\hline 6 & $\begin{array}{c}\text { Development of Whole (Agriculture) } \\
\text { Tribal Villages }\end{array}$ & 34 & 50 & 100 \\
\hline
\end{tabular}

Table.D Adoption categories of respondents

\begin{tabular}{|c|c|}
\hline Categories & Score Range \\
\hline High & $66.67-100$ \\
Medium & $33.34-66.66$ \\
Low & $0-33.33$ \\
\hline
\end{tabular}

Table.1 Significant of difference in overall knowledge of respondents about agriculture services

\begin{tabular}{|c|c|c|c|c|}
\hline \multirow[t]{3}{*}{ S.No. } & \multirow{3}{*}{ Services } & \multicolumn{2}{|c|}{ Knowledge } & \multirow{3}{*}{$\begin{array}{c}\text { t } \\
\text { value }\end{array}$} \\
\hline & & $\begin{array}{l}\text { Beneficiaries } \\
\mathbf{n}_{1}=30 \mathrm{f}(\%)\end{array}$ & $\begin{array}{c}\text { Non - Beneficiaries } \\
\mathbf{n}_{2}=\mathbf{3 0} \mathbf{f}(\%)\end{array}$ & \\
\hline & & MPS & MPS & \\
\hline 1 & $\begin{array}{l}\text { Agriculture Implements and } \\
\text { Distribution }\end{array}$ & 76.66 & 15.89 & $12.74 * *$ \\
\hline 2 & Vegetable Development & 71.87 & 59 & $15.07 * *$ \\
\hline 3 & Horticulture Development & 80.08 & 47.94 & $16 * *$ \\
\hline 4 & $\begin{array}{l}\text { Development of Barren Land through } \\
\text { Jatropha Plantation }\end{array}$ & 73.14 & 41.94 & $10.27 * *$ \\
\hline 5 & Livestock Development & 84.79 & 59.21 & $10.11 * *$ \\
\hline 6 & $\begin{array}{l}\text { Development of Whole (Agriculture) Tribal } \\
\text { Villages }\end{array}$ & 67.56 & 47.17 & $13.81 * *$ \\
\hline
\end{tabular}


Figure.1 Respondents overall knowledge in agricultural services

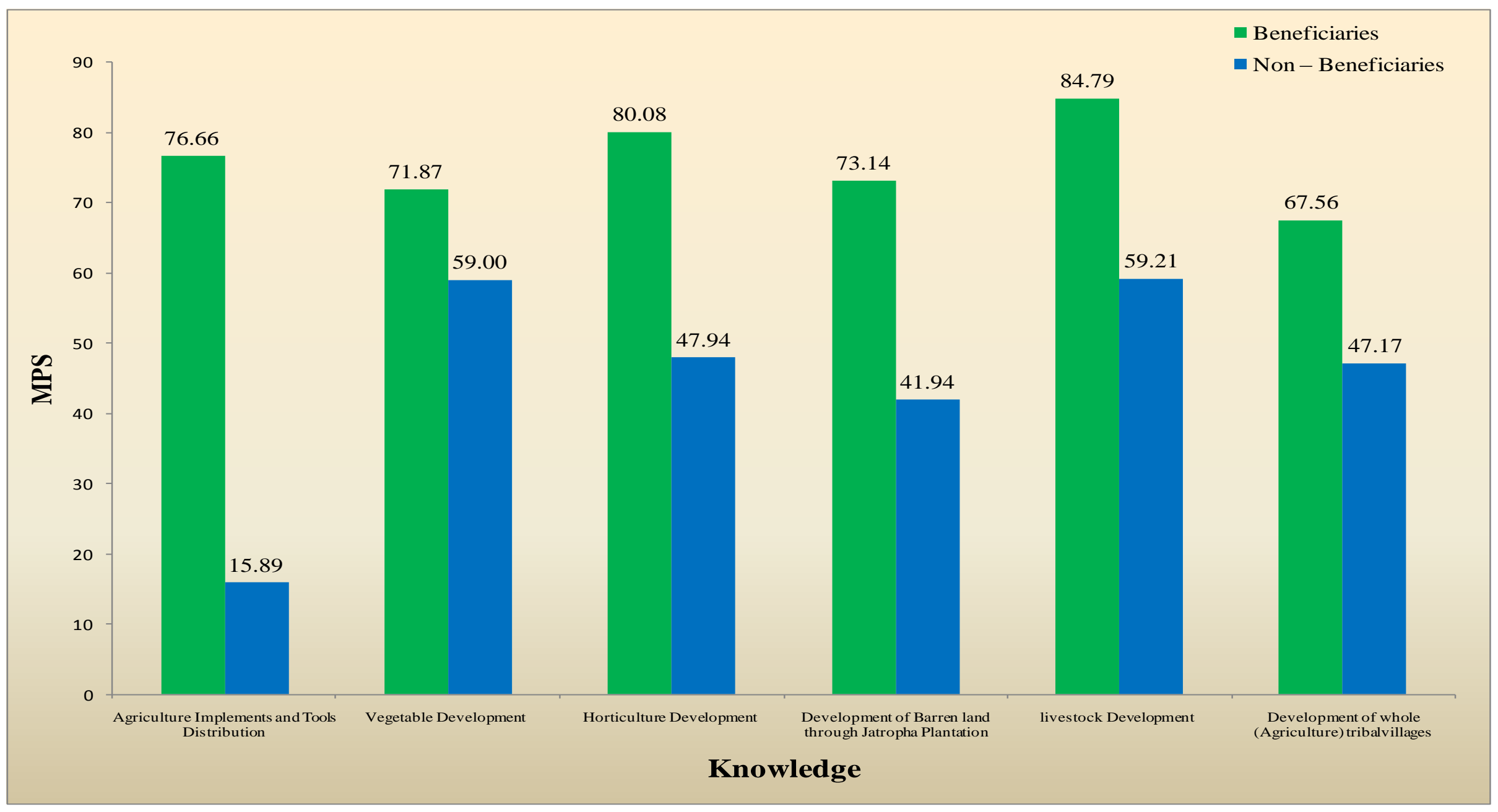


Figure.2 Overall adoption of improved practices of agricultural services among respondents

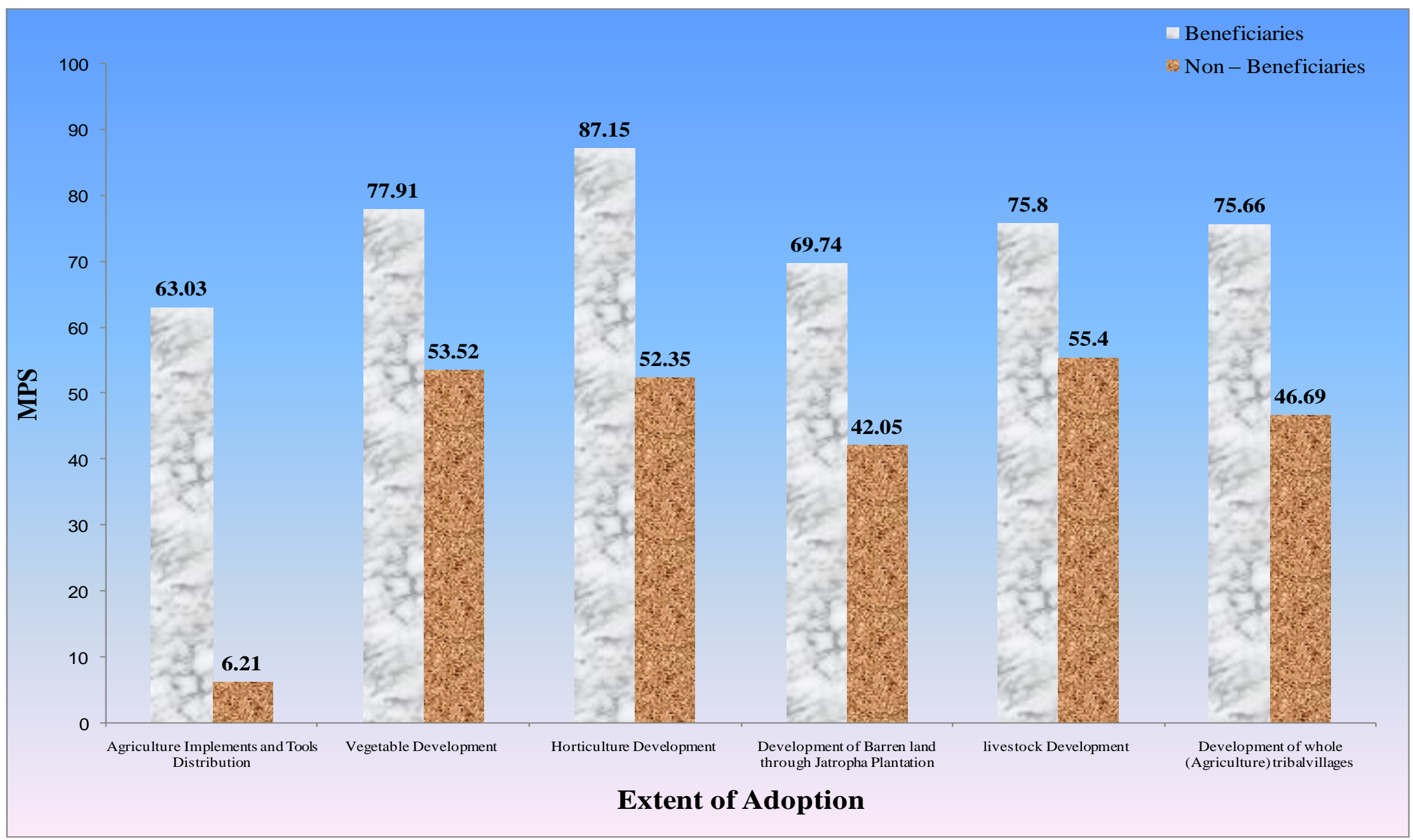


Figure.3 Gap in knowledge and adoption of Agricultural services among beneficiaries
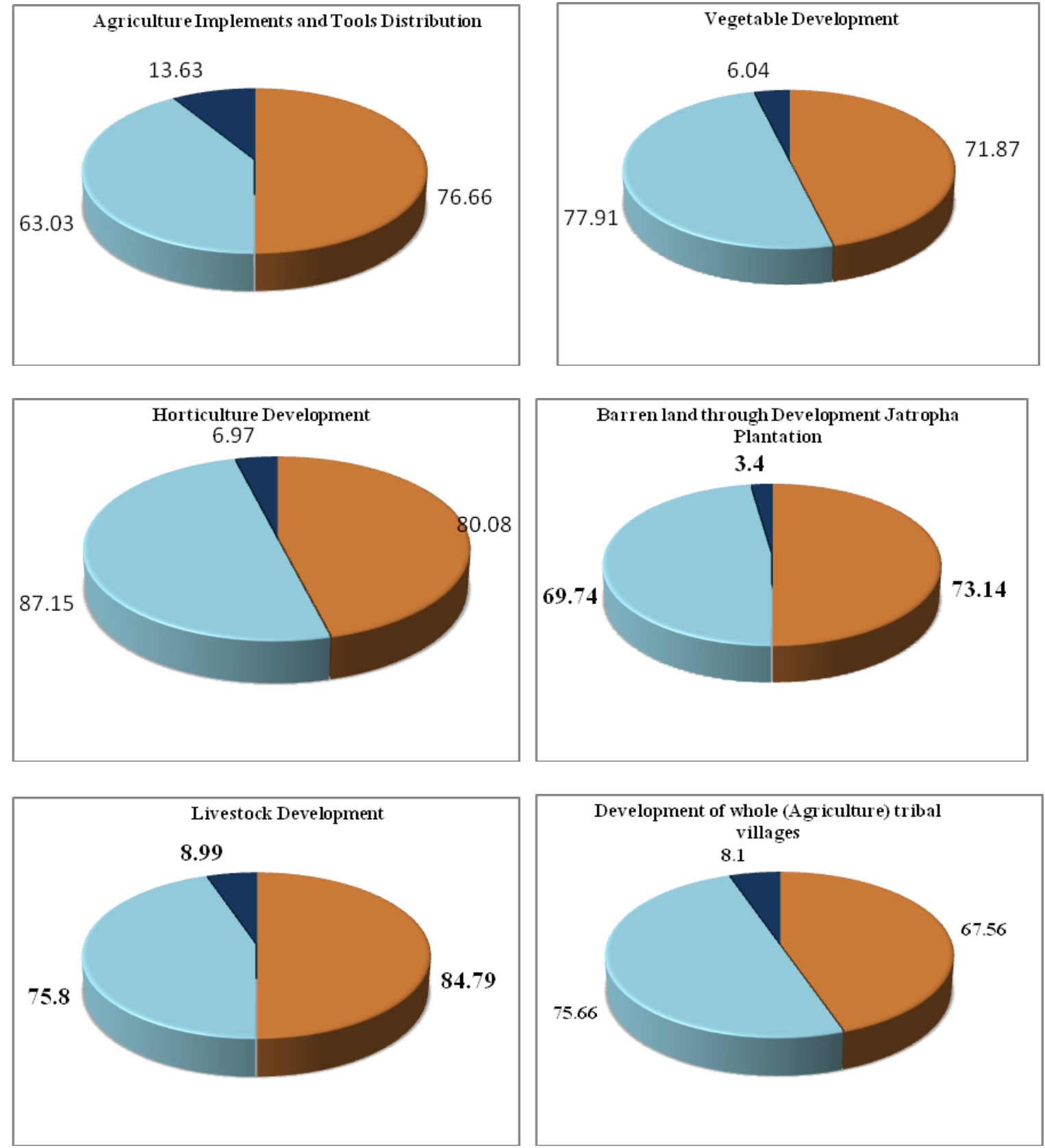

$\square$ Knowledge $\square$ Adoption $\square$ Gap $\%$ 
The knowledge scores for all the six agriculture services revealed that beneficiaries had good knowledge with MPS above 67.56. Similarly the adoption MPS (above 75.66) indicated high adoption in Vegetable development, Horticulture Development, Barren Land Development through Jatropha Plantation, Livestock Development and Development of Whole (Agriculture) Tribal Villages except Agriculture Implements and Tools Distribution with medium adoption. The gap in knowledge and adoption revealed that in three services viz. Agriculture Implements and Tools Distribution (13.63\%), Development of Barren land through Jatropha Plantation (3.4\%) and Livestock Development $(8.99 \%)$ was due to more knowledge than adoption while in other three services the gap was due to more adoption than knowledge i.e. in Vegetable Development (6.04\%), Horticulture Development (6.97\%) and Development of Whole (Agriculture) Tribal Villages $(8.1 \%)$.

It can be inferred from the table that in the services of Agriculture Implements and Tools Distribution, Barren Land Development through Jatropha Plantation and Livestock Development, knowledge was more but adoption was less means knowledge has not influenced the adoption but in other services viz Vegetable development, Horticulture Development and Development of Whole (Agriculture) Tribal Villages, the adoption was more as compared to knowledge means that beneficiaries were following the recommended practices even without having knowledge thus there is a need to increase knowledge with adoption about improved practices related to agriculture services for sustained use.

It can be concluded that, majority of the beneficiaries possessed good or average knowledge and non-beneficiaries possessed average or poor knowledge in various components of all the Agricultural Services viz. Agriculture Implements and Tools Distribution, Vegetable Development, Horticulture Development, Barren land Development through Jatropha Plantation, Livestock Development and Development of whole (Agriculture) Tribal Villages. In adoption of the Agricultural services, majority of the beneficiaries were in high and medium adoption categories in various components of all the Agricultural Services and few of the beneficiaries were in low adoption category while in case of non-beneficiaries all were in medium or low adoption categories in all the Agricultural Services.

Based on these findings it can be said that there is need to reduce the constraints as far as possible and increase the knowledge with adoption of various components of agricultural services for sustainable development with support of favourable opinion. This will further increase the income and thereby quality of life of the beneficiaries of the progrmme.

\section{References}

Akhter, J., Asiwal, B. L. and Hussain, A. 2013. Knowledge and Adoption of Animal Husbandry Practices among the Farmers of Sikar District of Rajasthan. Indian Journal of Extension Education and Rural Development 21: 196-199.

Bedi, M.S. 1995. Tribal Development in Rajasthan. Himanshu Publication, Udaipur. $\mathrm{p} 6$.

Brief view of development - Tribal Area Development Department (Government of Rajasthan). 20082009. Published by Manikyalal verma Tribal Research and Training Organization Area Development Department (Government of Rajasthan) 
Choudhary, L.R. and Punjabi, N.K. 2012. Knowledge of farmers about coriander production technology Rajasthan Journal of Extension Education 20: $233-237$.

Devi, L. 2013. Adoption of Dairy Farming Technologies by Livestock Farmers. Indian Research Journal of Extension
Education 13: 57- 61.

Rao, L.R., Shivamurthy, M., Shailaja Hittalamani and Lakshminarayan, M.T. 2007. Knowledge of vegetable growers regarding integrated pest management practices. Journal of Research ANGRAU 8: 248-251.

\section{How to cite this article:}

Sonali Sharma, H. R. Sain, B. L. Dangi, Rajshree Upadhyay and Bhupendra Upadhyay. 2020. Knowledge, Adoption and Significant Difference among Respondents of Agricultural Services (TADP). Int.J.Curr.Microbiol.App.Sci. 9(02): 2296-2305. doi: https://doi.org/10.20546/ijcmas.2020.902.260 